\title{
o caderno de recortes sobre educação do "Diario Official do Estado de São Paulo": indícios de cultura material na Escola Primária "Dr. Jorge Tibiriçá" (1930-1947)
}

Laerthe de Moraes Abreu Junior ${ }^{1}$

Senac-SP

\section{Resumo}

Este trabalho apresenta uma pesquisa em história da educação na área de cultura material escolar. Analisa o caderno de recortes sobre educação do Diario Official do Estado de São Paulo feito pelos educadores da escola primária "Dr. Jorge Tibiriçá" durante os anos de 1930 a 1947. Esta análise pretende mostrar indícios das práticas escolares que aparecem e se destacam em meio aos textos sobre aspectos legais da educação.

Palavras-chave: História da educação; Cultura material escolar; Práticas escolares.

\section{ABSTRACT}

This paper is a research about the history of education concerning the material school culture. It analyses the excerpts on education from the Diario Official do Estado de São Paulo that compose the notebook prepared by the educators of the primary school "Dr. Jorge Tibiriçá” from 1930 to 1947. It intends to show some traces of school practices found along the texts on educational legislation.

Keywords: History of Education; Material School Culture; School Practices. 
Ora, é claro que o grupo de disciplinas que chamamos indiciárias não entra nos critérios de cientificidade deduzíveis do paradigma galileano. Trata-se, de fato, de disciplinas eminentemente qualitativas, que têm por objeto casos, situações e documentos individuais, enquanto individuais, e justamente por isso alcançam resultados que têm uma margem ineliminável de casualidade...

Carlo Ginzburg, em Sinais, raízes de um paradigma indiciário

\section{INTRODUÇÃO}

Este trabalho se insere na perspectiva da história da educação investigada a partir da cultura material escolar. A feitura de um caderno de recortes selecionados do Diario Official do Estado de São Paulo durante os anos de 1930 a 1947, mais do que uma postura inflexível de normatizar uniformemente as ações cotidianas pautadas pelo fiel cumprimento dos ditames legais do Estado, mostra indícios singulares da organização da escola, geradas a partir das ações dos educadores anônimos que compuseram tal documento. E esse caderno sugere a presença da casualidade também no ato de lidar com fontes primárias. No meio de muitas centenas de materiais que compõem o acervo documental da Escola Dr. Jorge Tibiriçá, destaca-se o caderno de recortes, exemplar único e inconfundível, que convida a ser analisado, primeiramente por esse forte apelo de originalidade e, em seguida, pela riqueza dos textos que o compõem, pois ao deparar-se com um documento desse gênero, o pesquisador sente que está para entrar num domínio reservado e exclusivo daquela instituição que o gerou.

O próprio ato de escolher determinados textos para constituir o caderno, e não simplesmente colar todos os decretos, circulares e comunicados que eram publicados no Diario Official, já aponta para a necessidade de se ater a particularidades de cada instituição para que se compreenda em que base sociocultural se estabelecia o conjunto das práticas educativas ali vivenciadas cotidianamente. Este tipo de procedimento se faz, principalmente, pela atenção aos testemunhos materiais da história das instituições educacionais, tais como o caderno de recortes aqui trabalhado.

A opção de vincular a pesquisa na Escola Dr. Jorge Tibiriçá à cultura material escolar ${ }^{2}$ justifica-se pelo fato de que esta área tem se constituído num campo fértil de investigações, especialmente por contribuir para realçar dois 
planos de grande significação para pesquisas educacionais. O primeiro é o plano das práticas escolares, de forte tendência antropológica, pois trata prioritária, mas não exclusivamente, da ressignificação das ações e interações humanas realizadas dentro das escolas, pois o que está em destaque é a constituição de um plano abrangente de caráter histórico-sócio-cultural que envolve sujeitos, materiais e memórias, e que, portanto, ultrapassa os muros da escola e, mais, possibilita diversas abordagens e escolhas temáticas relacionadas com as ressonâncias dessas práticas escolares na sociedade da época e vice-versa.

O outro plano, que se desenha em conjunto com o anterior, é aquele dos aspectos mais visivelmente históricos, relacionados à análise das práticas em seu transcurso temporal, sua permanência e suas transformações. Aqui os materiais têm um valor incontestável, pois é principalmente através deles que se pode ressignificar a vida escolar em suas várias facetas: da composição e organização das salas de aula, analisadas a partir dos livros de registro de matrícula, que trazem dados importantes sobre a origem dos alunos, da profissão dos pais e responsáveis até as experiências mais claramente pedagógicas, encontradas nos planejamentos de professores, nos manuais escolares e nos cadernos de alunos. Ou ainda, pesquisar documentos únicos e singulares como o caderno de recortes, incentivado pela possibilidade de percorrer dezoito anos da vida da escola condensados num só material.

Muitas outras possibilidades de investigação se desdobram a partir desta visão em que a cultura material escolar é o centro de interesse. A complexidade desse campo de trabalho aponta para a necessidade de um esforço diversificado de pesquisas para abarcar todas as suas dimensões, tal como na urdidura de uma rede, em que cada ponto, isto é, cada realidade investigada somente é capaz de amarrar um nó, isto é, de dar partida à formação de um plano cognoscível, quando unido a um ou mais pontos.

Desta forma, se o caderno de recortes é o centro de interesse deste trabalho, ele só se destaca por existir dentro de uma escola, que por sua vez é a referência histórica mais marcante da educação pública na região onde se realizou a pesquisa. Assim, cada realidade investigada em sua particularidade remete-se ao contexto no qual foi gerada, e ela é apenas uma entre tantas outras possibilidades de abordagem de questões que estão indissoluvelmente ligadas: as práticas escolares, os materiais escolares, os sujeitos da instituição e a história da própria instituição. 


\section{A Escola Dr. Jorge TibiriçÁ̄}

Em Bragança Paulista, no Estado de São Paulo, encontra-se a Escola Dr. Jorge Tibiriçá, fundada em 1897. Resultado da reunião das escolas isoladas da localidade, sua criação não só foi um marco na cidade como teve decisivo papel histórico na implantação e difusão do ensino público regional. Atualmente, a escola que atende as quatro primeiras séries do ensino fundamental achase localizada no prédio inaugurado em 1909, construído dentro dos moldes da arquitetura escolar republicana do final do período, isto é, um edifício monumental em estilo neoclássico e estrategicamente situado na região central da cidade, de forma a se destacar do conjunto dos prédios urbanos e ser materialmente notada a importância que a nascente república conferia à educação.

O acervo de documentos da Escola Dr. Jorge Tibiriçá aparenta, primeiramente, o descaso com que as instituições educacionais lidam com sua própria história. Está guardado numa pequena sala do porão, sem ventilação, que é uma espécie de depósito de coisas velhas e sem mais utilidade, pois na mesma sala há uma grande quantidade de materiais displicentemente largados e desordenados em armários e estantes abarrotados, quando não em caixas de papelão sujas e gastas pelo tempo. São restos de cartazes e enfeites de festas ou comemorações da escola, do tipo "Dia do Índio" e "Dia da Árvore", que alguém um dia resolveu colocar ali. E ninguém mais ousou mexer naquele "tesouro". Os documentos, por sua vez, não tiveram melhor sorte. Distribuemse irregularmente pelos poucos móveis, alguns em pastas, outros soltos, e a maioria não possui identificação. Quando se procura uma lógica nessa distribuição não só não se encontra, como a tentativa de se buscar seqüências completas será uma frustração para aqueles que esperavam algum padrão que orientasse a investigação. Mas como sabem os pesquisadores de história, é sobre essa realidade fragmentária e descontínua que se faz seu trabalho.

Entretanto, um novo e atento olhar que busque nesse conjunto de materiais dispersos e incompletos indícios da individualidade dessa escola — pois as experiências educacionais são sempre singulares e únicas — vai encontrar pistas e rastros muito significativos das práticas escolares dessa instituição ao longo dos diferentes momentos de sua existência, entendendo-se de antemão que a totalidade das experiências não será jamais encontrada e que o trabalho do historiador não é o de reconstituir fielmente o passado, mas propor análises e interpretações sobre os dados existentes.

Entre muitas centenas de documentos encontrados, tais como livros de registros de matrículas, atas de reuniões pedagógicas, manuais de professo- 
res, diários de classe e prestações de contas, entre tantos outros, foi escolhido para este trabalho o livro de recortes do Diário Oficial do Estado de São Paulo montado entre os anos de 1930 e 1947.

\section{O Caderno de recortes do Diario Official do Estado de São PaUlo}

A escolha desse caderno, material singular e único, e também bastante incompleto para dar conta de todas as características sócio-educacionais dos anos 30 e 40 se justifica por dois motivos: o primeiro é que o caderno já é em si mesmo um indício, uma pista para a compreensão do modo como se organizava concretamente a vida diária naquela escola; o segundo, é que, feito a partir de recortes do Diario Official, estes podem ser considerados também como indícios e pistas, pois, ao serem selecionados para fazer parte do caderno, apontam para a necessidade de atentarmos para as razões dessa triagem.

Esse aparentemente simples caderno, desgastado e mal conservado, ${ }^{4}$ oferece inúmeras indagações, a começar pela própria época de sua existência. Durante as quatro primeiras décadas do século XX, a sociedade brasileira vivenciou embates relativos a projetos de educação pública em diferentes perspectivas: higienista, de formação moral e cívica e da psicologia experimental, mas todos sob a égide de um movimento fortemente nacionalista. Nos anos 30 houve a presença marcante no cenário educacional de intelectuais como Fernando de Azevedo, Anísio Teixeira e Lourenço Filho. É a época do movimento da educação renovada (lembremo-nos do "Manifesto dos Pioneiros") e da criação da Associação Brasileira de Educação (ABE) que tiveram grande influência nas propostas educacionais em todo o Brasil. Foi nessa década que se iniciou o governo de Getúlio Vargas, com a presença de Francisco Campos no recém-criado Ministério da Educação e Saúde Pública. Em seguida houve a longa gestão de Gustavo Capanema (1934 a 1945), que abrangeu o período ditatorial do Estado Novo (1937). Neste sentido, o caderno — principalmente a partir da leitura atenta do conteúdo dos "Comunicados", "Circulares", "Expedientes" e "Decretos” recortados do Diário Oficial e ali colados — nos traz a possibilidade de pensarmos a intencionalidade embutida na legislação oficial para a educação, isto é, nos convida a indagar sobre o propósito dos agentes educacionais da época.

No entanto, o indício mais forte que traz o caderno está na seleção dos recortes que o compõem. Por que em dezessete anos de existência só foram preenchidas sessenta das cem páginas do caderno, com alguns e não todos os 
recortes? Quais os critérios para a seleção desse material? E os recortes que faltam, por que não interessaram àqueles sujeitos? Quem foram esses agentes educacionais? Quais suas preocupações e objetivos? Que aproveitamento se fez, pelos educadores, da leitura daqueles textos? Algumas destas perguntas, certamente nunca terão resposta; entretanto, isto já sinaliza para a abrangência que um só documento, singular e único, nos oferece para a compreensão da história dessa escola.

\section{O início do caderno}

O caderno se inicia com uma circular datada de 26 de janeiro de 1930, enviada pela "Diretoria Geral da Instrucção Publica" e copiada com cuidadosa letra manuscrita na primeira folha. Diz a circular que "d'ora-avante, as determinações desta Directoria, que tenham caracter geral, não mais serão feitas por circulares, mas publicadas no 'Diario Official', donde devereis extrai-las para collecciona-las em livro especial". ${ }^{5}$ Qual a razão dessa circular? Forçar a adoção de um padrão para as condutas em todas as escolas do Estado ao obrigar os responsáveis a lerem diariamente o Diario Official ou favorecer a autonomia, já que cada escola fica responsável por colecionar seu "livro especial"?

\section{O modo de olhar os recortes}

Se é dominante a presença de questões legais e burocráticas nos recortes selecionados - e nem poderia ser outra a preponderância, já que o interesse maior é sobre a organização da vida cotidiana da escola e de seus agentes educacionais —, só o fato de permitir que a própria unidade escolar organize seu caderno abre caminho para uma relativa autonomia diante da normatização legal. Assim, embora colecionados em ordem cronológica, há recortes sem data e lacunas na seqüência das circulares do departamento de educação publicadas no Diario Official. É de se supor que todas as circulares sobre educação deveriam fazer parte do "livro especial"; ou não? Esta é uma questão que não terá resposta pois exigiria a manifestação daqueles sujeitos, hoje desaparecidos, que compuseram o caderno.

Porém, há um determinado modo de olhar os textos que pode ler, mesmo no árido universo da legislação e burocracia, indícios de práticas escolares bem peculiares que passariam despercebidas se mirássemos somente o contexto político educacional da época - um contexto dominado pelo governo ditatorial de Vargas — na busca da ideologia que emana das diretrizes 
oficiais, o que realmente está presente nas práticas escolares, mas não de forma absoluta.

De fato, o primeiro recorte evidencia a preocupação dominante que se estendeu durante as primeiras décadas do século passado, segundo Carvalho: "'Regenerar' as populações brasileiras, por meio da higiene e da educação". O texto de uma circular, de $\mathrm{n}^{\circ}$ 8, de 19 de fevereiro de 1930, diz o seguinte:

\section{Sr. Inspector..........}

Tendo-se verificado que a inspecção do asseio corporal e do vestuário das crianças escolares não está sendo realizado com o devido rigor, solicito vossas providencias para que a mesma se faça systematicamente, em todos os estabelecimentos de ensino publico, officializados, municipaes e particulares.

Essa pratica não só forma nas creanças ${ }^{7}$ hábitos de hygiene, como ainda, defendeas efficientemente, contra muitas moléstias nocivas e graves.

Essa preocupação, ou melhor, essa relação entre higiene e educação, fartamente analisada por historiadores da primeira metade do século XX, é de fato um apelo muito forte para os educadores nos procedimentos oficiais e vai aparecer ainda em outros textos do caderno. Na página do Diario Official de 25 de janeiro de 1935, colada à folha 14 do caderno, vê-se o desenho de um modelo para prédio para escola isolada. Logo abaixo do desenho da escola rural há uma série de textos e entre estes há um trecho que diz: "A ninguém é lícito desconhecer o valor de um predio escolar, quer sob o aspecto hygienico quer sob o aspecto pedagógico".

Anos mais tarde, em 1942, ainda se vê a preocupação com a higiene no comunicado sem data na página 39 (mas que pelo sentido do conteúdo e pela localização na página se refere ao início de outubro de 1942) alusivo à comemoração da "Semana da Criança". O texto solicita o atendimento a um programa "que conste de: higiene, moral, jogos esportivos, distribuição de alimentos, roupas, doces, brinquedos, excursões e visitas". O programa de higiene contempla os itens: higiene corporal, ou seja, asseio, banhos etc.; higiene do vestuário, como roupas adequadas às estações; higiene escolar, com o preparo para ir à escola, a apresentação pessoal, o material escolar em ordem, limpeza e economia, entre outros; higiene e habitação, como varrer, como remover o pó e assim por diante; higiene das moléstias comuns, em que se aborda como combater ou como evitar as moléstias mais comuns na infância: "gripes, desinterias $[s i c]$, sarampo, coqueluche, catapora, verminose, difteria, oftalmia; distúrbios do aparelho digestivo, etc."; e, finalmente, higiene mental, 
entendida como "aquisição de bons hábitos: bom humor permanente, constância e concentração no trabalho, coragem - domínio próprio, amor à verdade — honestidade, amor à ordem" e assim por diante.

Nesses três trechos pode-se aquilatar a importância oficial dada à relação entre higiene e moral, consideradas bases da vida social saudável e cujo cultivo deve constar do trabalho diário dos professores. Pela longa duração de sua presença no caderno, podem-se perceber as dificuldades encontradas para o cumprimento desta idealização, que perdurou por tanto tempo.

\section{4 grupos de recortes}

Mesmo tratando de conteúdos heterogêneos, alguns dos quais bem peculiares, é possível agrupar os recortes em quatro grandes grupos:

1) Aspectos legais, o que aparece em maior quantidade e que trata dos processos de remoção, de licenças, de afastamentos, de concursos de professores e demais funcionários escolares e ainda de outros processos.

2) Aspectos pedagógicos, em seu sentido lato, pois trata, entre outros assuntos, de orientação para trabalhos para o professor executar em sala de aula, sugestão de livros de leitura, seleção de livros didáticos e de programas disciplinares, entre outros.

3) Aspectos funcionais, que vão desde a orientação para a feitura e prestação de contas da caixa escolar, até a formação de bibliotecas, passando por temas como modelo para construção de prédios escolares e comunicados para fiscalização do ensino.

4) Aspectos cívicos, pois há alguns textos que tratam de comemorações, desde o Dia da Árvore ao aniversário do presidente.

Na impossibilidade de se fazer uma análise meticulosa de todos os recortes que compõem o caderno, foram selecionados para este trabalho apenas alguns textos que não só ilustrem os grupos aqui estabelecidos mas apontem para características indiciárias no mínimo curiosas e sobretudo reveladoras da intencionalidade sociopolítica que os órgãos oficiais da educação delegavam à escola.

Um recorte que convida à reflexão é o da página 9 do caderno, sem data, mas que pelos textos à vizinhança certamente é de 1934, e que diz: 
atendendo a uma solicitação da "Nestlé and Anglo-Sweiss [sic] Condensed Co.", deliberou [a Diretoria Geral do Ensino] a distribuição de alguns de seus produtos pelos alunos dos estabelecimentos de ensino do Estado [São Paulo], bem como, na ocasião, prelecionar aos escolares sobre o processo de fabrico e as virtudes do leite condensado.

Não há como se recusar a ver a ingerência de uma poderosa multinacional de gêneros alimentícios nos hábitos alimentares da população através de sua formação básica, na infância. O pior é que essa ação se fez através da escola, e, dada a antiguidade do recorte (1934), sabe-se lá que outras propostas do mesmo gênero não foram realizadas.

\section{A escola nova}

Um recorte também curioso é o que trata do programa escolar nos estabelecimentos de ensino primário. Colado à página 10 do caderno, também sem data, mas sobrescrito em letra manual: "Publicado na Folha da Manhã de 13-6-34", o texto diz o seguinte:

A Directoria do Ensino resolveu que em todos os estabelecimentos de ensino primario continuem em vigor os programmas elaborados em 1925 (Comunicado $\mathrm{n}^{\mathrm{o}} 21$, de 6 do corrente), recomendando aos professores que procurem observar a orientação aconselhada em suas indicações ...

Todavia o professor que preferir pôr em prática os processos da "escola nova" deverá, por intermédio da autoridade a que estiver subordinado, submetter previamente á aprovação do chefe do Serviço do Ensino Primario o projecto de programma que pretende desenvolver.

Disto pode-se concluir que apesar da presença destacada no cenário educacional de defensores da escola nova como Lourenço Filho e Fernando de Azevedo, a adoção dos processos desse tipo de educação não era feita unanimemente nem pela própria diretoria de ensino de São Paulo, uma das mais envolvidas nesse processo de "modernização". Aliás, o que se recomenda é de um conservadorismo explícito, pois a orientação é por manter os programas de 9 anos atrás, isto é, de 1925!

Outro recorte significativo é na verdade uma volumosa colagem de 34 páginas (207 a 240) da Revista da Educação, sem data, mas seguramente do final do ano de $1933 .{ }^{8}$ O interesse aqui está em primeiro lugar no grande nú- 
mero de páginas coladas, que abordam assuntos diversos: desde um decreto sobre a carreira do magistério público primário, que trata de classificação das escolas, remoções e concurso de ingresso, até um comunicado sobre bibliotecas e museus escolares. O recorte termina na segunda página de um artigo de Fernando de Azevedo, então diretor da escola Caetano de Campos, intitulado O livro e a escola nova, em que defende a posição da escola nova em favor da leitura, chamando de "ignorância ou má-fé" a atitude dos críticos que viam nos métodos ativos a desvalorização da leitura. Esse é o único recorte da revista e, se bem que a Revista de Educação não seja o Diário Oficial, traz os textos legais de interesse ao professorado. Poderíamos perguntar o porquê dessa opção. Poderíamos, também, perguntar por que o texto de Fernando de Azevedo está incompleto, mas não há material para responder a estas questões. Fica, entretanto, o registro da criatividade desse procedimento, pois a revista pode até substituir o Diario Official, e a atenção dada pelos agentes educacionais da Escola Dr. Jorge Tibiriçá daquela época, à renovação dos métodos de aprendizagem, é entrevista tanto nos documentos sobre a formação da biblioteca como no fragmento do texto de Fernando de Azevedo.

\section{Autoridades escolares}

Entre os comunicados, circulares, expedientes e decretos que regulam a vida funcional da escola, ou seja, na determinação dos procedimentos sobre remoção e afastamento de professores, sobre feriados e férias escolares, encontra-se um recorte sem título e sem data, mas colado na página seguinte a um comunicado de 21 de janeiro de 1933, que "dispõe sobre transferencia de professores primarios, visando a reunião de conjuges”. Lê-se que há 137 requerimentos nesse sentido. O que interessa aqui é notar e destacar os procedimentos para tal, desde os documentos exigidos como "atestado de autoridades, preferivelmente escolares, de que o interessado vive em pleno regime matrimonial" até os critérios de ordem de preferência sendo o primeiro "a reunião de casais de professores" e o último, "reunião de conjuges, um dos quais exerça profissão liberal", depois de "reunião de conjuges, um dos quais seja empregado ou auxiliar no comercio". No caso dos documentos exigidos, é digno de nota, senão por mera curiosidade, a exigência da comprovação da vida matrimonial abonada preferivelmente por uma autoridade escolar. É instigante refletir sobre o papel das autoridades escolares na sociedade da época. Seriam, elas, verdadeiramente valorizadas à época a ponto de deliberarem até sobre a veracidade da vida conjugal dos professores? É também curioso notar 
que nos critérios de preferência para a reunião de cônjuges, o último deles seja o dos profissionais liberais, menos valorizados que os empregados e auxiliares do comércio. São pistas singulares que apontam, mais que informam sobre a forma de organização da sociedade e seus valores, sobrepujando, hoje, o mero entendimento dos dispositivos legais contidos nos textos que foram guardados no caderno.

\section{Festas e comemorações}

São encontrados, também, circulares e comunicados sobre festas e comemorações. A começar pela celebração do "Dia Pan-Americano". No comunicado n.51, de 21 de janeiro de 1935, para "Delegados Regionaes do Ensino e directores de Escolas Normaes e Gymnasios”, está escrito que:

esta Directoria resolveu marcar o dia 13 de abril proximo para a celebração do "Dia Pan-Americano". O objectivo que se teve em vista ao estabelecer-se o "Dia Pan-Americano", por sua elevação faz com que seja a data observada de maneira carinhosa em todo o Continente.

São sugeridas atividades tais como: Historia da America, Significação do Pan-Americanismo, Propositos do "Dia Pan-Americano", Bandeiras das Nações Americanas e Americanos ilustres, entre outras.

Essa comemoração aparece ainda algumas vezes mais no caderno e seu último registro é de 1947, quando a data destinada para a celebração foi 14 de abril. Tentava-se manter o mesmo espírito celebrativo de doze anos antes: "Tais solenidades devem revestir-se de grande brilho para que cale fundo no ânimo dos escolares a necessidade da formação de um espírito de solidariedade continental".

Pode-se perguntar se essa idéia seria uma iniciativa do Estado Novo, mas lê-se que o pedido partiu da União Pan-Americana com sede em Washington, isto é, uma proposta de amplitude internacional. Em 1935, o dito comunicado sugeria que aquela era "uma opportunidade para que os estudantes voltem a attenção para as relações tradicionalmente intimas que têm unido as Republicas americanas.... Hoje, a referência ao panamericanismo está totalmente concentrada nas competições de atletismo, que se repetem a cada quatro anos, em que não se busca mais "a conveniencia de se manterem e estreitarem essas relações", mas somente a disputa entre desportistas e ginastas 
rivais para ganharem medalhas de ouro, prata e bronze, exaustivamente expostas na programação esportiva da televisão.

Há muitas outras comemorações, como a Festa da Ave na circular sem data, mas que colada à página 16 do caderno revela que 1935 foi o ano do festejo. Diz o Programma para a Festa da Ave: "Nas escolas primarias: Canções de louvor ás aves - Representações — Dar liberdade a passaros — Mostrar em pequenas palestras o que devemos ás aves”.

Um ano mais tarde, o decreto n.7612, de 25 de março de 1936, "fixa datas para a realização das festas dos Animaes e das Arvores" e diz:

Considerando que as datas fixadas pelo dec. n. 5.525, de 19 de maio de 1932, não são as que mais convêm a essas festas, confórme representação do Conselho Florestar [sic] do Estado, decreta:

Art. $1^{\underline{0}}-$ As festas dos Animaes e das Arvores serão realizadas, respectivamente, nos dias 15 de março e 21 de setembro de cada anno.

Podemos ler aqui indícios de algum tipo de preocupação como as que hoje denominamos ecológica? O contexto é outro, mas fica patente a preocupação longínqua (desde 1932) com uma proposta de educação para preservar a natureza.

Outros três recortes sobre festejos merecem destaque:

1) O Mês da Bandeira Nacional — na circular n.32, de 14 de setembro de 1940, lê-se que:

De 19 de outubro a 18 de novembro, fica reservada a $3^{\underline{a}}$ hora para a realização de atividades em tôrno da Bandeira Nacional ... Cada grupo escolar confeccionará a sua Bandeira Nacional. O diretor do Grupo organizará para isso uma comissão de alunas, dentre as que mais se salientam pela conduta e aplicação. Essa comissão será dirigida por professoras.

O texto não esconde laivos de misoginia ao referir-se somente a alunas e professoras para se incumbirem de tarefas de corte e costura como se fossem, naturalmente, habilidades só das mulheres.

2) O aniversário da Constituição vigente - na circular n.57, de 3 de novembro de 1941. Trata-se da Constituição do regime do Estado Novo, que cerceava os direitos e a liberdade e impunha um estado ditatorial à sociedade brasileira. E o texto da circular propunha comemorar a data da seguinte maneira: 
Nas escolas primárias, a comemoração consistirá em aulas, dadas no dia 8, aos alunos dos 3.os e 4.os anos, devendo estes executar trabalhos escritos sobre o fato explicado e desenhos alusivos a prosperidade do Brasil (projeto de cartazes).

Nas escolas normais oficiais, municipais e particulares e nos ginásios, o programa se desenvolverá no próprio dia 10, dele podendo constar: parada dos alunos, demonstração de educação física, competições esportivas, sessão solene com a presença do corpo discente. Além desta parte deverão os alunos, durante a semana, executar trabalhos escritos sobre a Constituição ou capítulo da mesma aproveitadas as aulas de História do Brasil e de Sociologia.

3) A data natalícia do chefe da nação - em recorte sem data, mas que pela localização no caderno é de março de 1943. Diz o texto:

Transcorre no dia 19 do corrente mais um aniversário do exmo. Sr. dr. Getulio Vargas, eminente chefe da nação.

Venho recomendar a essa Repartição, com o maior empenho, que essa data se comemore condignamente em todas as escolas primárias, secundárias, normais e profissionais do Estado. Deverão realizar-se, em cada uma, festividades cívicas nas quais se porá em destaque a figura ilustre do presidente da República, cuja biografia será feita por um professor, realçando-se notadamente, no plano nacional, a sua grande obra de união e de progresso material e cultural do Brasil; e, no plano internacional, as sábias diretrizes, graças às quais a nossa Pátria está colocada definitivamente entre as nações de primeira grandeza no cenário mundial.

Os diretores dos estabelecimentos deverão comunicar a esta Secretariai, através dessa Repartição, não só a realização da solenidade, como também o respectivo programa.

Esses recortes que compõem os dois últimos tópicos evidenciam claramente a utilização, e até mais: a manipulação dos conhecimentos históricos e sociais dentro dos regimes de exceção. As autoridades procuram conduzir a maneira como os personagens e seus atos devem ser entendidos. E nada melhor para isto do que a utilização do espaço escolar para tal finalidade e, ainda mais, numa época em que o acesso à informação era bem incipiente, quando comparado aos nossos dias. Além disso, os meios de comunicação estando censurados impedia-se uma ampla discussão crítica do regime vigente. $\mathrm{O}$ controle era tão grande que ao final da circular sobre a comemoração do aniversário de Vargas pede-se que os diretores prestem conta de como realizarão o evento. 


\section{Livros didáticos}

Um assunto que hoje é bastante discutido, a presença dos livros didáticos nas escolas, causa até uma certa surpresa por já estar presente nas preocupações da década de 1940, pois é o que se lê em pelo menos três circulares. Primeiro em março de 1942, "o Diretor Geral do Departamento de Educação solicita dos senhores delegados que ainda não o fizeram, o ensino das comunicações relativas à escolha de livros didáticos para o presente ano".

Depois, em março de 1944, procura-se dar uma melhor organização na escolha dos livros através de um comunicado que diz:

Mostruário de Livros Didáticos - Em todos os grupos escolares deve haver, organizado até junho próximo futuro, um mostruário de livros didáticos primários autorizados, sob a guarda direta e responsabilidade, de preferência do porteiro.

... Constituirão tal mostruário apenas os livros cujos autores ou editores os remeterem gratuitamente.

... Em relação a consulta feita, o Diretor Geral do Departamento de Educação recomenda que, na hipótese de ser escolhido livro do qual haja falta no mercado livreiro, consultados por ofícios seus editores e as grandes livrarias da Capital, é permitido ao próprio professor a escolha de novo livro da relação oficial. Devendo o diretor fazer a respeito ata suplementar, assinada por ele e pelo professor.

Aqui se nota mais uma tentativa de controle das autoridades governamentais sobre a ação didática do professor. Outro dado relevante é a existência de uma lista autorizada e oficial de livros didáticos recomendados, tal como hoje é feita pelo Ministério da Educação porém dentro de outro contexto, posto que em nossos dias não há manifestação de controle político-ideológico, e sim científico-acadêmico.

No entanto, parece que a seleção de livros didáticos transformou-se em propaganda dentro das escolas, pois a circular n.77, de 3 de outubro de 1944, remete a um decreto de 1938 para impedir que os professores tornem-se comerciantes de livros:

\section{PROPAGANDA DE LIVROS DIDÁTICOS}

O artigo 26 do decreto-lei 1006 de 30 de dezembro de 1938, proíbe a prática de atos favoráveis ou desfavoráveis a determinado livro didático, dentro das escolas e o artigo 27 veda a professores ou a quaisquer autoridades escolares de caráter técnico ou administrativos tornarem-se agentes ou representantes de auto- 
res, editores e livreiros, para a propaganda de livros escolares, ainda que tais se pratiquem fora das repartições ou estabelecimentos em que trabalhem.

O parágrafo único do artigo 26 estabelece, porém, que a proibição de atos de propaganda dentro do estabelecimento não impede que os autores, editores e livreiros ou representantes seus (não autoridades escolares) remetam exemplares de obras de uso autorizado, bem como circulares prospectos ou folhetos explicativos sobre os mesmos aos professores ou diretores das escolas.

A leitura desses recortes sobre livros didáticos é um convite a refletirmos sobre a necessidade de as pesquisas em história da educação se debruçarem mais sobre a história dos materiais didáticos. Quase sempre tratados como agentes secundários e quase sempre mal conservados, quando não jogados fora, materiais como os livros didáticos trazem indícios fundamentais sobre como as práticas escolares se organizavam no cotidiano das escolas, desde a influência nos conteúdos a serem ministrados até a divisão do tempo da aula mediada pelas lições contidas nas páginas dos livros.

\section{A Segunda Guerra Mundial}

Pode-se notar que mesmo feito na intencionalidade de ser lido como um documento oficial, o caderno traz informações sobre o cotidiano da sociedade. Desta forma, é interessante investigá-lo, também, sobre o modo como a Segunda Guerra Mundial interferiu ou apareceu nesse cotidiano. Pois se o caderno abrange todos os anos da guerra (1939-1945), vale a pena examinar de que maneira essa realidade está presente ao longo dos textos selecionados. A análise feita com essa finalidade mostrou que há poucas referências à guerra e que o tratamento dado ao tema pode até numa leitura superficial indicar que esta pouco influiu no cotidiano das escolas. As referências aparecem com pouco destaque, quase sempre diluídas no meio de outros assuntos. A primeira aparição da palavra guerra está num recorte de 1943 cujo título é Campanha da Borracha:

O Departamento de Educação, confiando no patriotismo do professorado paulista recomenda que, em todos os estabelecimentos de ensino primário, secundário e normal do Estado seja promovido, de $1^{\circ}$ a 15 de julho próximo, a CAMPANHA DA BORRACHA, como parte de nossa cooperação ao esforço de guerra do Brasil.

... O que se fizer nesse sentido, será levado à conta de contribuição valiosa ao aparelhamento das forças armadas brasileiras. 
Na página 44 no mesmo recorte já mencionado anteriormente sobre o mostruário de livros didáticos há um subtítulo BÔNUS DE GUERRA, que diz o seguinte: "Os bônus de guerra adquiridos com numerário proveniente da venda de material resultante da Campanha pelo Metal, são considerados como patrimônio das caixas escolares".

E, finalmente, já no pós-guerra, um comunicado de 11 de julho de 1946 traz no meio do texto sobre as recomendações para a comemoração da $\mathrm{Se}$ mana da Criança uma referência à guerra, que soa mais como uma utilização indevida dos efeitos da guerra para justificar a situação de fome e miséria em que vivia grande parte da população brasileira:

O tema escolhido para o ano presente foi "A criança, as atividades agrícolas e a alimentação", o mesmo, aliás, de 1945, justificando-se sua continuação não só nos expressivos resultados alcançados no exercício anterior como, também, no fato de perdurar, ainda, no Brasil, o fenômeno da carência alimentar, conseqüência própria da Guerra que está, naturalmente, a exigir a mais ampla divulgação da necessidade de aproveitamento da terra, dos conhecimentos úteis ao seu cultivo e ao preparo racional de alimentos.

\section{O final do caderno}

O último recorte é uma folha inteira do Diario Official do dia 11 de junho de 1947, dobrada sem estar colada entre as páginas 59 e 60 do caderno. Nessa folha há uma circular do Diretor-Geral do Departamento de Educação, Dr. [sic] Francisco Brasiliense Fusco, em que agradece aos auxiliares e às autoridades de ensino o apoio à Campanha de Educação de Adultos Analfabetos no Estado. Entretanto, o caderno não termina aí. Após dezenas de páginas em branco, já no final do caderno, das páginas 98 a 100, aparecem textos rascunhados, sem data, sobre problemas comuns de redação, orientando o emprego de verbos e pronomes entre outras formas de escrita correta. Na última página do caderno estão colados quatro recortes intitulados "Questões vernaculas" de Napoleão Mendes de Almeida, sem data e sem a referência aos jornais dos quais foram extraídos. Novamente, poderiam ser feitas ilações, todavia sem muita consistência, sobre a preocupação na época em que aconteceram essas intervenções no caderno com a forma correta de redação. Contudo, o mais evidente é a utilização do caderno pelos agentes educacionais da Escola Dr. Jorge Tibiriçá, naquela ocasião, para finalidades não previstas quando de sua inauguração no início dos anos 30. 


\section{CONCLUSÃO}

As particularidades aqui destacadas desse singular material são apenas pequenos indícios do muito que se pode fazer em análises desta natureza. Se observado do ponto de vista estritamente formal, o caderno pode ser erroneamente interpretado como um documento menor, ou um mero objeto de uso particular e cotidiano. Mas é justamente aí que reside seu interesse. Por se tratar de um material de uso cotidiano, sua finalidade está voltada para a vida interna da instituição. Mesmo que o conteúdo central do caderno seja a legislação escolar daquele largo período de 1930 a 1947, a concretização da feitura do caderno oferece um elemento peculiar para análise que é a forma inigualável como foi montado e desse modo chegou até nossos dias. Naturalmente, há também limites para a utilização de materiais como esse para a compreensão dos processos educativos, pois não é possível fazer uma avaliação definitiva das práticas escolares a partir desse caderno.

A intenção deste trabalho foi mostrar a complexidade que investigações do gênero acarretam. Um material aparentemente simples e que pode ser entendido à primeira vista como algo pouco importante, oferece, na verdade, variadas formas de procedimento. A análise empreendida, propositalmente não é conclusiva nem definitiva, e deixa aberta a possibilidade de outros trabalhos de pesquisa para completar ou mesmo confrontar o que foi feito aqui.

Em suma, este trabalho tentou ilustrar como se faz uma investigação no campo da cultura material escolar e com isso tornar patente a singularidade daquela escola. Este procedimento permite que se conheçam por dentro as práticas institucionais, ao invés de estudar a educação somente através dos textos legais, e mais: sem perder, obviamente, a visão do contexto da época. As práticas escolares configuram facetas muitas vezes desconhecidas que sobrepujam até as análises dos processos formais e burocráticos, fatos tão banais que intentam cobrir a riqueza histórico-cultural dos afazeres do cotidiano escolar. $\mathrm{O}$ dado mais inquietante é que as investigações em educação ainda se dedicam muito pouco a esses aspectos de interesse convergente à história, à antropologia e à cultura escolar.

\section{NOTAS}

${ }^{1}$ Pós-doutor pela Universidade do Minho, Portugal, assessor educacional da GCO do Senac-SP.

${ }^{2} \mathrm{O}$ campo de pesquisas da cultura material escolar se aproxima, quando não se engaja fir- 
memente no campo da cultura escolar, qual seja o da formação de sujeitos históricos na escola e das relações entre a cultura da sociedade e a cultura promovida na escola para esta formação. A diferença está na ênfase, ou melhor, no grau de importância que a cultura material escolar dá aos objetos concretos produzidos para e pela cultura. Vários textos oferecem sustentação epistemológica para a discussão proposta neste trabalho, tais como: BERRIO, J. (Ed.) La cultura escolar de Europa: Tendências históricas emergentes. Madrid: Biblioteca Nueva, 2000; HÉBRARD, J. Por uma bibliografia material das escritas ordinárias: o espaço gráfico do caderno escolar (França — séculos XIX e XX). Trad. Laura Hansen. Revista Brasileira de História da Educação. Campinas: Autores Associados, n.1, p.11541, jan./jun. 2001; FERNANDES, R., FELGUEIRAS, M. L. (Org.) A escola primária: entre a imagem e a memória. Porto: Fundação Dr. António Cupertino de Miranda, 2000; JULIA, D. A cultura escolar como objeto histórico. Trad. Gizele de Souza. Revista Brasileira de História da Educação. Campinas: Autores Associados, n.1, p.9-43, jan./jun. 2001; MAGALHÃES, J. Roteiro de Fontes para a história da educação. Lisboa: Instituto de Inovação Educacional, 2001; VIÑAO, Antonio. Tiempos escolares, tiempos sociales. Barcelona: Ariel, 1998. ${ }^{3}$ No campus da Universidade São Francisco, em Bragança Paulista, encontra-se o Centro de Documentação e Apoio à Pesquisa em História da Educação - CDAPH, que através de seu Núcleo de Estudos e Pesquisas em Cultura Material Escolar desenvolveu de 2002 a 2004 um projeto de pesquisa sobre a memória educacional da Escola Dr. Jorge Tibiriçá. Esse projeto contou com a participação não só de pesquisadores do CDAPH, como também de estudantes do Programa de Estudos Pós-Graduados em Educação e do Curso de Graduação em Pedagogia daquela universidade.

${ }^{4}$ Trata-se de um caderno retangular de capa dura medindo $33 \mathrm{~cm}$ por $22 \mathrm{~cm}$. Traz o título Registro de circulares expedidas pela Directoria Geral de Instrucção Publica. Possui cem folhas brancas pautadas onde estão colados recortes de diversos tamanhos, todos amarelados pela ação do tempo. Há alguns recortes dobrados, outros rasgados, mas a maioria apresenta boa condição de leitura.

${ }^{5}$ Por tratar-se de uma fonte primária única e exclusiva, as citações dos textos do caderno de recortes não serão remetidas às notas, mas transcritos os trechos de interesse no corpo do trabalho e com a grafia original.

${ }^{6}$ CARVAlHO, M. M. C. de. Quando a história da educação é a história da disciplina e da higienização das pessoas. In: FREITAS, M. C. de. História Social da Infância no Brasil. São Paulo: Cortez, 1997, p.284.

${ }^{7}$ Em dois parágrafos do mesmo texto a palavra criança está redigida de forma diferente.

${ }^{8}$ Estas páginas fazem parte da Revista de Educação, v.4, n.4, de dezembro de 1933. Isto se pode confirmar pelo texto final do recorte: o famoso artigo de Fernando de Azevedo O livro e a Escola Nova, publicado nesse número da revista. 